\title{
Lab-On-A-Chip: A Mechanistic Approach for Biological Screening
}

\section{Enamul Hoque ${ }^{1 *}$ and R G S V Prasad ${ }^{2}$}

${ }^{1}$ Department of Mechanical, Materials and Manufacturing Engineering, University of Nottingham Malaysia Campus, JalanBroga, Semenyih, Selangor, Malaysia ${ }^{2}$ Biomedical and Pharmaceutical Technology Research Group, Nano Research for Advanced Materials, Bangalore, Karnataka, India

Micro fabrication techniques have wide range of applications in the field of life science. Microfluidic devices are now playing vital roles in drug discovery, cell biology, neurobiology, pharmacology and tissue engineering. These micromechanical devices are capable of manipulating even single component/object like cells. Lab-on-achip (LOC) uses electrical, magnetic, and mechanical phenomena for cell trapping, sorting, analysis and fusion. By far, several approaches have been attempted to fabricate these microfluidic devices but generally two approaches, like in-plane and out-of-plane have been found to be practically workable, and out of these two the in-plane is considered to be the most convenient approach to fabricate such device with state-of-the-art planar technology [1]. This comprises of surface micromachining and different techniques of silicon etching that provides higher degree of flexibility. Microfluidic techniques are now used in various pharmacological screening studies to understand cell-cell interactions, homotypic and heterotypic intercellular cross talks in fundamental processes, such as tissue morphogenesis, and also provides cell-based and organ-based platforms for preclinical drug and toxicity testing [2,3]. In addition to these, LOCs are also used to assess contractility of muscles (Muscle-on-chips). A device was developed using muscular thin film (MTF) technology that made it possible to evaluate the contractility of both striated and smooth muscle simultaneously on the same chip [4]. The micro-total analysis systems complemented with optical and impedimetric readouts were used in quantitative characterization of changes in cell metabolism and morphology as a response to toxin exposure [5]. This principle is used in designing a biosensor as an alternative for skin irritation studies. Hydrogel-based diffusion chip with electric cell-substrate impedance sensing (ECIS) was also developed for cell viability assay and drug toxicity screening [6]. This model was used to simulate the drug diffusion system that involved a hydrogel-based tissue-mimicking structure with microfluidic channel having high stability. Consistently $\mathrm{IC}_{50}$ values were obtained by using this method [6]. Microfluidic systems consisting of micro analytical hybrid system are also used to screen the cytotoxic effects of chemotherapeutic agents (5-fluorouracil) on cancer cells [7]. A three-dimensional (3D) tumor spheroid chip was developed to evaluate pharmacokinetic (PK) aspects by balanced droplet dispensing system [8]. These types of chips help in predicting the elimination parameters like, half-life and other parameters in this microenvironment. Further advancement in technology with these microfluidic devices started with the organs-on-chips. Microfluidic liver-on-a-chip was designed along with microsomal enzymes to mimic the liver's biochemical processes [9]. This liver-on-chip would help in predicting biotransformation process of food and drug components, and these results can be applied in vitro. The unique advantages of these technologies involve their compactness and precise controllability that render them to be utilized in various biological applications. This review indicates that the LOC technology can bridge the gap between engineering and pharmaceutical/biological fields to provide much better therapeutic solutions to the end users.

\section{References}

1. Lin L, Pisano AP (1999) Silicon processed micro needles. IEEE J Microelectromech Sys 8: 78-84

2. Neuzi P, Giselbrecht S, Lange K, Huang TJ, Manz A (2012) Revisiting lab-on-achip technology for drug discovery. Nat Rev Drug Discov 11: 620-632.

3. Whitesides GM (2006) The origins and the future of microfluidics. Nature 442 368-373.

4. Grosberg A, Nesmith AP, Goss JA, Brigham MD, Megan L, et al. (2012) Muscle on a chip: In vitro contractility assays for smooth and striated muscle. J Pharmacol Toxicolo Methods 65: 126-135.

5. Hofmann U, Michaelis S, Winckler T, Wegener J, Feller KH, et al. (2013) A whole-cell biosensor as in vitro alternative to skin irritation tests. Biosens Bioelectron 39: 156-162.

6. Tran TB, Cho S, Min J (2013) Hydrogel-based diffusion chip with Electric Cellsubstrate Impedance Sensing (ECIS) integration for cell viability assay and drug toxicity screening. Biosens Bioelectron 50: 453-459.

7. Jedrych E, Flis S, Sofinska K, Jastrzebski Z,Chudy M, et al. (2011) Evaluation of cytotoxic effect of 5 -fluorouracil on human carcinoma cells in microfluidic system. Sensor Actuat B-Chem 160: 1544-1551.

8. Kim T, Doh I, Young-Ho Cho (2012) A3D tumor spheroid chip with the pharmacokinetic drug elimination model developed by balanced droplet dispensing. Sensor Actuat B: Chem 174: 436-440.

9. Lee J, Kim SH, Young CK, Choi I, Sunga JH (2013) Fabrication and characterization of microfluidic liver-on-a-chip using microsomal enzymes. Enzyme and Microbial Technology 53: 159-164.
*Corresponding author: Md Enamul Hoque, Department of Mechanical, Materials and Manufacturing Engineering, University of Nottingham Malaysia Campus, JalanBroga, Semenyih, Selangor, Malaysia, Tel: +6 038924 8367; E-mail: enamul.hoque@nottingham.edu.my

Received February 18, 2014; Accepted February 18, 2014; Published March 03, 2014

Citation: Enamul Hoque M, Prasad RGSV (2014) Lab-On-A-Chip: A Mechanistic Approach for Biological Screening. J Appl Mech Eng 3: e127. doi:10.4172/21689873.1000e127

Copyright: () 2014 Enamul Hoque M, et al. This is an open-access article distributed under the terms of the Creative Commons Attribution License, which permits unrestricted use, distribution, and reproduction in any medium, provided the original author and source are credited. 